influence on the prevalence rate of postpartum depression.

It is regrettable that Longhurst and Weiss should take the liberty of misinforming your readership with these false allegations. Readers may draw their own conclusions from the evidence in print.

Ghubash, R., Hamdi, E. Bebbington, P. E. (1992) The Dubai Community Psychiatric Survey: prevalence and sociodemographic correlates. Social Psychiatry and Psychiatric Epidemiology, 27, 53-61.

— Abou-Saleh, M. T. \& Daradkeh, T. K. (1997) The validity of the Arabic Edinburgh Postnatal Depression Scale. Social Psychiotry and Psychiotric Epidemiology, 32. 474-476.

O'Hara, M.W. Swain, A. M. Rates and risk of postpartum depression - a meta-analysis. International Review of Psychiatry. 8. 37-54.

M.T. Abou-Saleh, R. Ghubash Department of Psychiatry \& Behavioural Sciences, Faculty of Medicine \& Health Sciences, United Arab Emirates University, Al Ain, United Arab Emirates

Editorial comment: Copies of the two articles referred to in the preceding correspondence were sent to four senior editors of the British Journal of Psychiatry, all of whom found substantial similarity between the two papers. Those concerned by this matter might also like to look at a third paper by the same authors (Ghubash et al, 1997).

Authors submitting papers to the British Journal of Psychiatry (serially or otherwise) with a common theme or using data derived from the same sample (or a subset thereof) must send details of all relevant previous publications, simultaneous submissions, and papers in preparation. Failure to do so may arouse criticism and censure.

A paragraph to this effect will be added to our Instructions to Authors with immediate effect.

Ghubash, R., Abou-Saleh, M. T. \& Daradkeh, T. K. (1997) The validity of the Arabic Edinburgh Postnatal Depression Scale. Sociol Psychiotry and Psychiatric Epidemiology. 32. 474-476

Greg Wilkinson Editor. British Journal of Psychiatry. 17 Belgrave Square, London SWIX BPG

\section{Ethnicity in psychiatric epidemiology}

Sir: Singh's (1997) editorial on race, ethnicity and culture was timely and welcome. If there is any field in which these issues need to be aired, it is psychiatry. I had hoped that the British Medical Journal's guidelines would be an impetus for other journals to follow suit and develop their own editorial policies on research into ethnicity, culture and race (Anonymous, 1996). In this light, I am happy that Singh's five guiding principles so closely echo my own work (McKenzie \& Crowcroft, 1996) and that of Senior \& Bhopal (1994).

There are some points, however, which may need further discussion. It should be stated explicitly that epidemiology alone may not be a sensitive enough tool for cross-cultural research. Dr Singh emphasises the need for large-scale studies so that confounders can be measured, but measuring confounders does not necessarily produce valid categories.

The epidemiological approach often sacrifices validity and detail for measurability (Pope \& Mays, 1995). This can cause problems in the field of culture and ethnicity, where validity is important. The simple rule of thumb that 1 multiplied by $0=0$ and 100 multiplied by $0=0$ should be kept in mind. If you measure something badly, larger numbers will not help you.

A lot of groundwork needs to be carried out before large epidemiological studies are performed, in order to avoid problems of misclassification. The two main problems of misclassification - bias, leading to false and misleading findings (always difficult to ignore from large epidemiological studies), and non-differential classification, leading to a failure to detect important differences between groups - need to be avoided through good study design and are difficult or impossible to correct at a later stage by any statistical trickery.

Poor understanding of the nature of ethnicity and culture underpins its poor measurement and the poverty of coherent testable hypotheses. Qualitative methods such as ethnography, which often use small sample groups, can be more powerful tools for understanding culture and ethnicity and can help in hypothesis generation. Qualitative and quantitative investigation are not mutually exclusive; qualitative methods can be used to set the hypotheses for large-scale epidemiological studies and to make sense of the results gained from epidemiological studies.

The need to 'unpack' cultural and ethnic variables is also stated by Singh as important. However, it is not always desirable or even possible to 'unpack' culture or ethnicity. Ethnicity and culture are social and psychological constructs that are context driven. They are complex entities made up of interrelated factors. It is difficult to know how each factor affects the whole. Controlling for one factor may weaken the validity of the whole construct. Reductionism can lead to circular arguments. For instance, it is common to control for socio-economic status when looking at ethnic differences. However, it may be that these socio-economic differences are mediated by institutional racism, and the experience of them in the context of racism are catalysts and perpetuating factors for psychological and social changes which produce identity, differences in disease incidence and service use.

Despite this caveat, unpacking could be of great importance if it is used to produce multi-dimensional instead of categorical representations of culture and ethnicity.

Research into the validity and use of race, ethnicity and culture needs to be ongoing. It was one of the nine points proffered for improving measurement of ethnicity by Senior \& Bhopal (1994) and it is as true today as it was in 1994.

Anonymous (1996) Style matters. Ethnicity, race and culture: guidelines for research, audit and publication. British Medical Journal, 312, 1094.

MeKenzie \& Crowcroft, N. S. (1996) Describing race ethnicity and culture in medical research. British Medicol journal, 312, 1054.

Pope, C. Mays, N. (1995) Reaching the parts that other methods cannot reach: an introduction to qualitative methods in health and health services research. British Medical Journal, 311, 42-45.

Senior, P. A. Bhopal, R. (1994) Ethnicity as a variable in epidemiological research. British Medicol Journol, 309. $327-330$.

Singh, S. P. (1997) Ethnicity in psychiatric epidemiology: need for precision. British journol of Psychiatry. 171. 305-308.

K. McKenzie Department of Social Medicine, Harvard Medical School, 641 Huntington Avenue, Boston, MA 02115, USA

\section{Psychiatrists' attire revisited}

Sir: The report by Gledhill et al (1997) highlights patients' views on psychiatrists' attire. Psychiatric patients preferred consultants to wear suits, though doctors in suits were perceived to be the least friendly, least easy to talk to and least understanding. The authors suggest that consultants exchange suits for less formal wear, offsetting a slight loss of perceived competence for better communication. 